\title{
Quality and Pollution Control Technologies for Water, Air, and Soil
}

\author{
Josiane Nikiema, ${ }^{1}$ Evans M. Nkhalambayausi-Chirwa, ${ }^{2}$ and Yves Andrès ${ }^{3}$ \\ ${ }^{1}$ Department of Chemical/Biotechnological Engineering, Université de Sherbrooke, Sherbrooke, QC, Canada J1K 2R1 \\ ${ }^{2}$ Department of Chemical Engineering, University of Pretoria, Pretoria 0002, South Africa \\ ${ }^{3}$ Department of Energetic Systems and Environment, GEPEA UMR CNRS 6144, École des Mines de Nantes, 44307 Nantes, France
}

Correspondence should be addressed to Josiane Nikiema, josiane.nikiema@usherbrooke.ca

Received 21 September 2010; Accepted 21 September 2010

Copyright ( $\odot 2010$ Josiane Nikiema et al. This is an open access article distributed under the Creative Commons Attribution License, which permits unrestricted use, distribution, and reproduction in any medium, provided the original work is properly cited.

This special issue presents scientific papers originating from 4 continents and addressing important environmental issues. Indeed, environment is today a major issue in several countries. New or stricter regulations on the release of several pollutants or greenhouse gases are being implemented all around the world. Consequently, the followup and control of pollutants being rejected becomes necessary.

The use of plants, microorganisms, or isolated enzymes and other biomaterials in environmental treatment is well known, but many researchers try to understand the involved mechanisms with the goal of optimizing and intensifying the efficiency of pollution removal processes. Three papers were more specifically dedicated to this area. The first paper studies the seasonal and spatial changes of microorganism communities in constructed wetlands, a community level physiological profiling analysis, proposed by Chazarenc et al. The second paper, from Nikiema and Heitz, investigates the use of inorganic packing materials during methane biofiltration. After the microbial involved processes, the third paper presents the production of ligninolytic enzymes by whiterot fungus/Datronia sp/.KAPI0039 and their application for reactive dye removal, by Vaithanomsat et al.

The use of new or advanced processes to control water pollution with recalcitrant pollutants from various origins is also described in this special edition. The fourth paper proposes the simultaneous use of ozone and oxygen for the reduction of the chemical oxygen demand of an effluent generated by a paper processing plant (Terry). In the fifth paper, a combined AOP/Biological system is tested for the treatment of various recalcitrant organic compounds (Makgato and Chirwa). Advanced processes are also applied, in the sixth paper, to the removal of organic matter from landfill leachate ( $\mathrm{Li}$ et al.). Still for landfills, a study by Umar et al., assessing the pollution potential of leachate in Malaysia, is proposed (the seventh paper). In the eighth paper of Qiu et al. gives an overview of the nitrogen and phosphorous removal in municipal wastewater treatment plants in China. All these articles answer to the need to protect the integrity of natural water resources especially in this day and age when clean water is becoming scarce due to extensive pollution and urbanisation.

Accepted papers also include a study conducted by Chazarenc et al. on the movement of pollutants and global water balance of a wetland system (the ninth paper). Finally, the tenth paper was published on the efficiency of treatment of wastewater streams in power generation plants for recirculation using Koch Membranes (Jassim).

The sources of some toxic gaseous pollutants such as dioxins are presented in the eleventh paper (Wielgosinski), and methods to reduce such emission of pollutants to the atmosphere are discussed. On the other hand, the monitoring and modeling of the trends of some air pollution precursors in atmosphere are the subjects of the twelfth paper proposed by Al-Salem and Khan.

Finally, two papers focused on soil/sediments pollution, by studying the nitrate and ammonia nitrogen losses in surface runoff (Zhang et al., the thirteenth paper) and the fate of heavy-metal pollutants in sediments (Martin et al., the fourteenth paper). Overall, the fifteenth paper (Zadnik) reminds us of the importance of protecting the environment since pollution may have a detrimental effect on health.

Worldwide, the environmental market represents around $\$ 800$ billion and the global need of for environmental technologies, able to control pollution in air, water and soil, 
is in continuous increase. This special edition is therefore a prominent source of reliable scientific information on environment, its protection, and the future challenges that, as a society, we should face to win the battle against air, water, and soil pollution.

Josiane Nikiema

Evans M. Nkhalambayausi-Chirwa Yves Andrès 

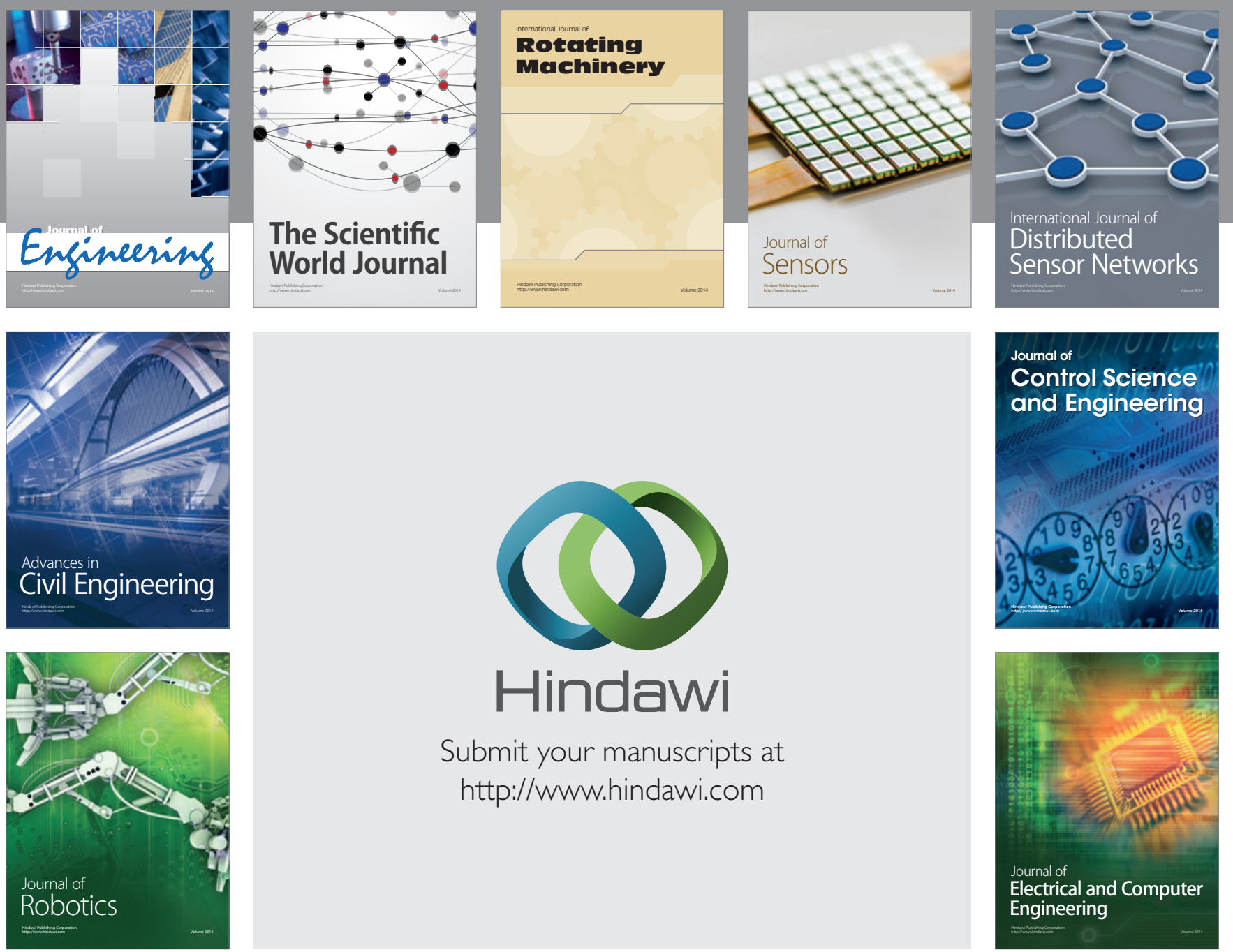

Submit your manuscripts at

http://www.hindawi.com
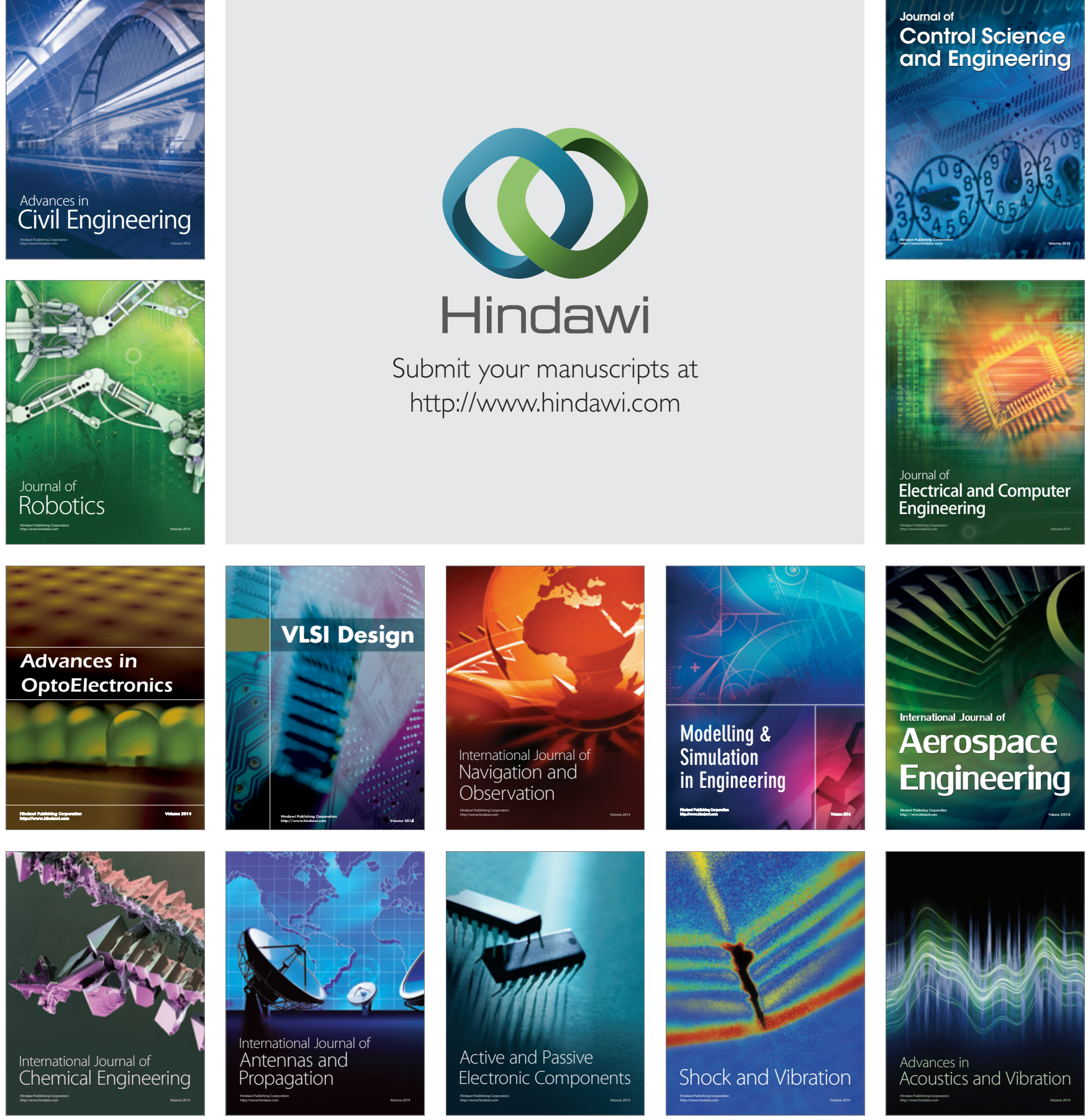